\title{
Extraneural metastases in ependymoma of the cauda equina
}

\author{
LUCIEN J. RUBINSTEIN AND WILLIAM J. LOGAN ${ }^{1}$
}

\author{
From the Department of Pathology (Neuropathology), Stanford University School of Medicine, Stanford, \\ California, U.S.A.
}

SUMMARY A case of ependymoma of the cauda equina, presumably originating from the filum terminale in a girl aged 17 at the onset of illness, eventually developed remote metastases in the lungs, pleura, and one para-aortic lymph node. This case is compared with three other previously reported examples. The unusual features in the present instance were (1) the total length of the clinical history, amounting to 29 years; (2) the development, six years after the removal of the original spinal tumour, of another ependymomatous mass in the fourth ventricle, interpreted as a rostral metastasis that seeded via the cerebrospinal fluid; and (3) the demonstration of anaplastic cytological changes at the primary site, interpreted as the result of irradiation. The salient aspects of this and the three other reported cases are briefly reviewed, and the pathway of distant dissemination, resulting from venous permeation at the primary site, is emphasized.

It is now well recognized that intracranial gliomas may, in certain cases, develop extraneural metastases. This event is determined in virtually all instances by previous operative decompression (Russell and Rubinstein, p. 219, 1963; Smith, Hardman, and Earle, 1969). Examples of this complication in intraspinal gliomas remain, however, very uncommon, and to date only three acceptable cases, verified at necropsy, of metastasizing ependymoma of the cauda equina have been reported (Weiss, 1955; Sharma, 1956; Patterson, Campbell, and Parsons, 1961). The examples recorded by Weiss and by Patterson and his colleagues were tumours which recurred on two or more occasions after the initial operation, and were remarkable in that remote metastases developed 10 and 17 years respectively after the onset of the disease. The purpose of this paper is to report a fourth example, in which the length of the illness extended over 29 years. An unusual circumstance in this case was the surgical removal, six years after the initial operation, of a metastatic deposit from the fourth ventricle, the residuum of which could still be demonstrated at necropsy 21 years later. This case exemplifies, therefore, the protracted clinical evolution that may attend the growth of this type of glioma, even when it culminates in the development of remote

${ }^{1}$ Present address: Department of Neurology, Johns Hopkins School of Medicine, Baltimore, Maryland, U.S.A. deposits. Of additional interest was the demonstration, at necropsy, of marked anaplastic cytological features at the primary site, interpreted as the result of irradiation.

\section{CASE REPORT}

A.S. (P.A.S.H., No 06-21-35). A white female, 46 years old at the time of death, first experienced, at the age of 17 , low back and radiating right sciatic pain. This was intermittent at first, then became constant and progressive, and accompanied by right leg weakness. In June 1941, two years after the onset of symptoms, myelography revealed a complete block at the level of the second lumbar segment. Lumbar laminectomy was followed by the subtotal resection of a soft, brownish vascular intradural tumour of the cauda equina. A sleeve of growth that covered the nerve roots could, however, not be removed. Postoperative irradiation $(1600 r)$ was delivered to the lumbosacral area.

The symptoms remitted, but recurred three years later, and additional irradiation ( $750 r$ ) was given to the lumbar region. This was followed by marked clinical improvement that lasted for two years. A further relapse was again treated with a course of radiotherapy to the lumbar region (100 $r$ ) in July 1946.

Meanwhile, in October 1945, she had begun to complain of headaches, neck pain, and intermittent nausea and vomiting, and because of the suspicion of neoplastic recurrence in the cervical area, was given a total dose of $1,000 r$ to that region. After a brief relief, the intracranial symptoms worsened during the following year, 
and she developed progressive unsteadiness of gait, diplopia, blurring of vision, dizziness, syncopes, and irritability. On examination in August 1947, at the age of 25 , she had a positive Romberg sign, right adiadochokinesia, horizontal nystagmus on lateral gaze to the right, bilateral papilloedema, and a left sixth cranial nerve weakness, as well as sensory changes in the distribution of L5 and S1 roots on the right and L5 on the left. $A$ radiograph of the skull showed widening of the sella turcica and depression of its floor, suggesting an expanding intracranial lesion. Suboccipital craniotomy disclosed a tan gelatinous tumour occupying the cisterna magna and extending down to the second cervical segment, apparently emanating from, and filling, the fourth ventricle. The tumour, which was attached to the roof of the ventricle and to the left cerebellar hemisphere, was entirely removed except for its attachments. Postoperative irradiation was directed to the posterior fossa via two lateral fields $(1,000 r$ each), to the upper cervical area $(300 r)$, and to the lumbosacral region (700 r).

During the next seven years the patient did fairly well, except for frequent bladder infections. She maintained moderately good function of her lower extremities, with slight weakness and numbness only. During the subsequent seven years, however, low back and radiating leg pain, and impairment of lower limb functions, manifested as hypalgesia and weakness, became progressive. She also developed urinary incontinence, and indwelling catheterization became necessary. Meanwhile, she underwent a normal pregnancy and delivery at the age of 34 , and a hysterectomy with cystocoele repair at the age of 36 .

When she was first admitted at the Stanford University Hospital in 1961, at the age of 38 , spinal radiography revealed extensive destruction of the lower lumbar and upper sacral vertebrae and of the left sacroiliac joint, associated with a soft tissue mass. Needle biopsy in the left sacral area confirmed the presence of recurrent growth.

Supervoltage irradiation $(5,000 r$ over four weeks) was delivered to the lumbosacral area with no improvement. She then underwent a bilateral ventral quadrantic thoracic cordotomy at T2-3 segment for pain. This was successfully alleviated for a time, and, except for frequent urinary tract infections, she did well for four years, when right sciatic pain recurred. This became intractable, and, in 1967, complete transection of the cord at T6 was performed. By then, total destruction of the sacrum, the upper half of the left ilium and the fifth lumbar vertebra was evident radiologically, with involvement of the left acetabulum and of the left 11 th and 12 th ribs. During the subsequent months she progressively deteriorated, had recurrent pain and episodes of urinary infection associated with ureteric obstruction, and developed anaemia, severe emaciation, and multiple decubitus ulcers. She died on 28 May 1968, 29 years after the onset of her illness.

NECROPSY FINDINGS (8F-217). At necropsy, a large necrotic, haemorrhagic retroperitoneal mass, measuring approximately $12 \mathrm{~cm}$ in diameter, had destroyed the two lower lumbar vertebrae, the sacrum, left ilium and left 11 th and 12 th ribs, and infiltrated the adjacent erector spinae muscles. A large right-sided retroperitoneal abscess containing approximately $300 \mathrm{ml}$. light green pus was present. Tumour partly obscured by reddish-brown thrombus grossly permeated both common iliac veins and plugged the lower part of the inferior vena cava up to within $2 \mathrm{~cm}$ of the ostia of the renal veins. Both ureters were embedded in growth, and were constricted and kinked. The kidneys showed bilateral hydronephrosis and chronic pyelonephritis. Posteriorly, tumour was attached to the distal part of the spinal cord and to the roots of the cauda equina. Numerous infected sinus tracts linked the growth to the subcutaneous tissues, and, on the left, a number of them opened onto the skin surface.

One enlarged lymph node, measuring $2 \times 1 \times 1 \mathrm{~cm}$, situated anteriorly to the abdominal aorta, was entirely replaced by greyish-yellow tumour. A well-circumscribed greyish-white firm nodule, measuring $1 \mathrm{~cm}$ in diameter, was found in the upper lobe of the right lung. No other metastatic masses were noted grossly in the general necropsy.

Apart from scarring over the inferior surface of the cerebellar hemispheres, the brain was externally normal. Coronal sections of the cerebrum revealed mild ventricular dilatation only. The wall of the fourth ventricle showed on the right a flat greyish irregular nodule, measuring $5 \mathrm{~mm}$ in diameter by $3 \mathrm{~mm}$ in thickness, which appeared fused with the otherwise smooth ependyma. Most of the fourth ventricle was empty. In the spinal cord, a segment of necrotic tissue replaced the parenchyma at the 6tho thoracic level, where the total cordotomy had been performed. Below this level, the crossed corticospinap tracts were softened and demyelinated.

MICROSCOPICAL STUDY The large invasive lumbo-sacrat mass consisted of moderately cellular tumour separated by an abundant connective tissue stroma. Most cells were delicately elongated and fibrillated, and usually unipolar. Others showed a less distinct cell margin, with a more compact syncytial, almost epithelial appearance. Elsewhere the tumour was more loose textured, the cell elements tending to be stellate, with fine radiating processes. In most places, the cytology was remarkably uniform. The cells contained small distinct round or oval nuclei, with a delicate chromatin membrane, a nucleoplasm of moderate density, and a finely punctate chromatin net. In these areas, mitotic figures were absent.

In several fields the tumour formed a delicate garland-like, almost papillary pattern in which the cells were closely aligned and extended their parallel processes to the fibrous or vascular stroma (Fig. 1). These processes all tapered to a point and did not show any foot plate expansions. The nuclei were usually remote from these cytoplasmic attachments.

Under oil immersion, sections stained with Mallory's phosphotungstic acid haematoxylin demonstrated in several places single or clustered blepharoplasts and cilia immediately adjacent to the tumour nuclei. They were most easily found in the more compact epithelial-like areas, and were usually not demonstrable in fields containing the perivascular pseudorosettes. No ependymal rosettes were found.

Massive necroses were present. The tumour paren- 


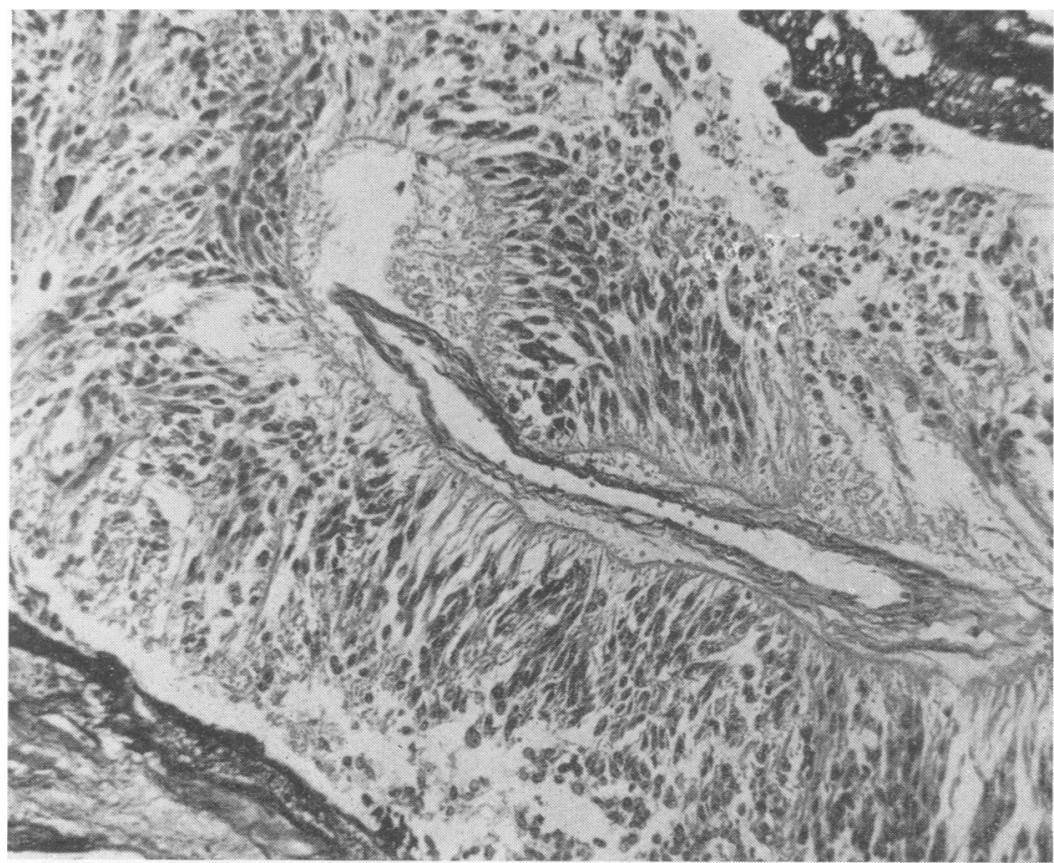

FIG. 1. Invasive lumbosacral tumour at necropsy. Arrangement of finely fibrillated tapering cells in perivascular pseudorosettes. Note lakes of darkly staining fibrinoid material, resulting from irradiation, in upper right and lower left. Mallory's phosphotungstic acid haematoxylin $\times 160$.

chyma was permeated by lakes of eosinophilic fibrinoid material. Much of the vascular connective tissue stroma showed either extensive fibrinoid necrosis or marked acellular fibrous hyaline thickening. Various stages of vascular thrombosis and organization were found. Some of the fibrous connective tissue stained reddishbrown with van Gieson, and was congophilic. Birefringence accompanied the congophilia. These changes were interpreted as the result of irradiation.

In addition, considerable cellular atypia and pleomorphism were evident in parts of the necrotic growth invading the sacrum and the iliac veins. The tumour cells were enlarged, plump and rounded, the cell processes were lost, and there was a marked increase in the nucleocytoplasmic ratio. The cells were frequently giant and multinucleated and the nuclei often contained one or more conspicuous nucleoli (Fig. 2). Mitotic figures, both typical and atypical, were common. Whereas in some fields the tumour cells maintained a relative degree of uniformity and were partitioned by a delicately vascular connective tissue stroma (Fig. 2), in others this pattern was wholly lost, and the cells were entirely anaplastic, with highly irregular, bizarre, and often giant forms (Fig. 3).

Review of the neoplasm originally removed from the lumbosacral region 27 years before death, and of the needle biopsy of the lumbosacral mass performed eight years before death, disclosed fragments of loosely arranged and moderately cellular fibrillated neuroglial tumour, the cells of which had small delicate elongated nuclei and demonstrated an attachment of their processes to the supporting blood vessels (Fig. 4). The histological appearances were identical with the loose textured areas seen at necropsy.

Sections from the fourth ventricle tumour removed 21 years before death demonstrated identical tissue. The small residual plaque of growth found at necropsy to be adherent to the right lateral wall of the fourth ventricle was again similar, except for the presence of marked irradiation changes in the rich vascular stroma. No cellular atypia was found. Microscopic tumour extended through the foramen of Luschka to enter the lateral recess. One small microscopic nodule of ependymoma was found attached to the floor of the fourth ventricle.

Sections from the upper lobe of the right lung, the lower lobe of the left lung, and from the grossly enlarged para-aortic lymph node demonstrated metastatic tumour composed of discrete clumps and nests of delicate fibrillated cells identical with those in the lumbosacral mass (Fig. 5). A few deposits were situated beneath the pleura, or extended along the pleural margin to form small dome-shaped elevations. The cells were often orientated by a long tapering process towards either the supporting blood vessels or the fibrous edge of the deposit (Fig. 6). In places they were cuboidal or low columnar, and aligned in an abortive attempt to form 


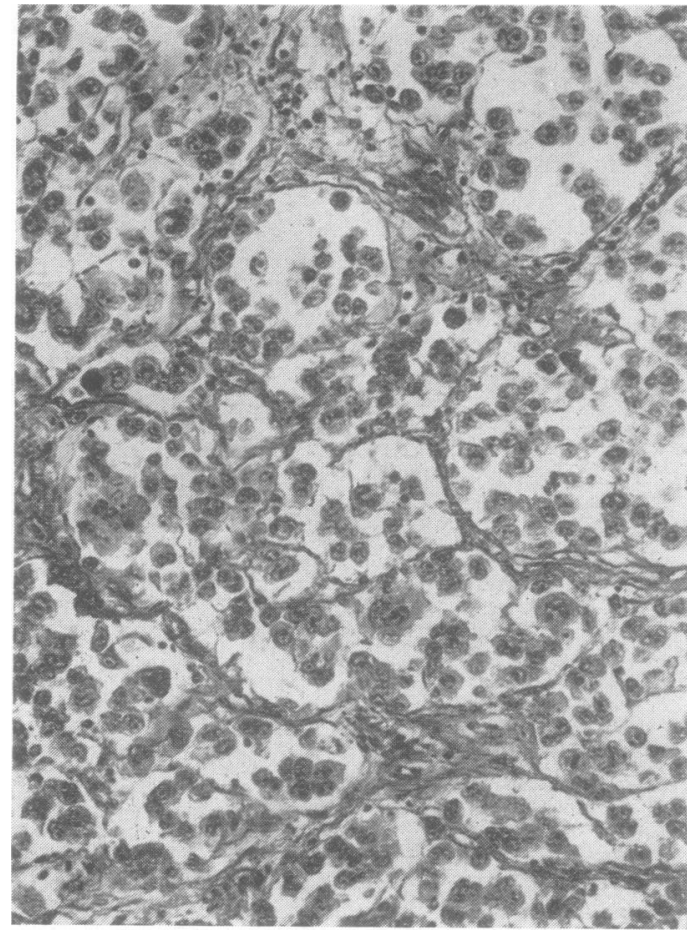

FIG. 2. Anaplastic tumour invading sacrum. Groups of cells are partitioned by a delicately vascular connective tissue stroma. Note giant cells and prominent nucleoli. Mallory's PTAH, × 200.

ependyma-lined spaces (Fig. 7). In one area, a definite ependymal rosette was found: as shown in Fig. 8, the tumour cells surrounded a pinpoint central channel, along which blepharoplasts were identifiable. Elsewhere the cells were arranged in small nests of irregular outline and frequently had an epithelial appearance. Clusters of blepharoplasts or small cilia were often seen in their cytoplasm. Anaplastic cell forms such as were demonstrated at the primary site were not found, but mitotic figures were fairly numerous among the tumour elements that occupied the lymph node.

The 6th and 7th thoracic segments of the spinal cord were replaced by a thick ring of collagenous tissue surrounding a central cavity that was filled with compound granular corpuscles and in which nodules of peripheral aberrant neurites were present, mostly adjacent to blood vessels. The cuneate tracts showed severe demyelination above this level, and the pyramidal tracts showed demyelination below. In the first and second thoracic segments, a glial scar was found in the ventral quadrants on either side. Several nerve roots of the cauda equina showed focal demyelination; others were completely demyelinated and fibrosed.

\section{DISCUSSION}

Microscopical study of this case leaves little room

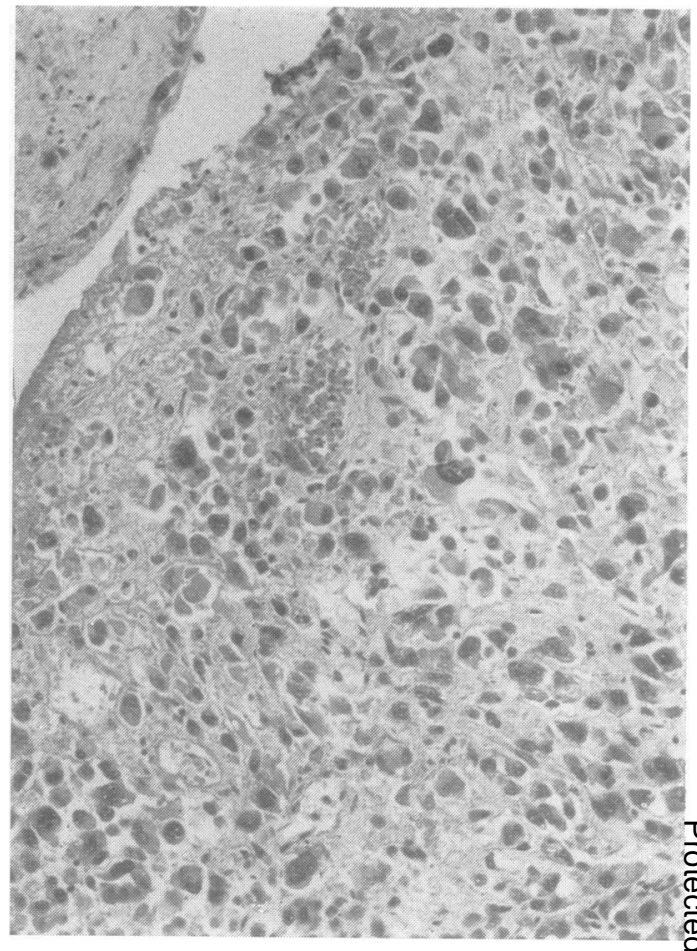

FIG. 3. Entirely anaplastic tumour permeating the lume of an iliac vein. $H$ and $E, \times 160$.

for doubt that the tumour which originally arose in the region of the cauda equina was an ependymoma. The main architectural feature at the primary site consisted of clusters and lobules of elongated, delicate fibrillated cells with tapering processes, containing small regular nuclei with a finely stippled chromatin net. An arrangement of radiating tapering cytoplasmic processes orientated towards the blood vessel walls was frequent. Typical ependymal rosettes were not seen at the primary site, but blepharoplasts were demonstrated. The pattern of perivascular pseudorosettes was similar to that seen in astroblastomas, but no foot plates originating from the cell processes were present and the tumour nuclei were remote from the blood vessel walls. A more typical arrangement of small compact clusters of polygonal cells with well-defined borders and an epithelial appearance, occasional groupings in small rosette-formations around a minute central circular space, and abortive ependymal-tubule formations were demonstrated in the extraneural deposits, in particular the para-aortic lymph node.

Ependymomas account for the overwhelming majority of gliomas arising in the region of the cauda 


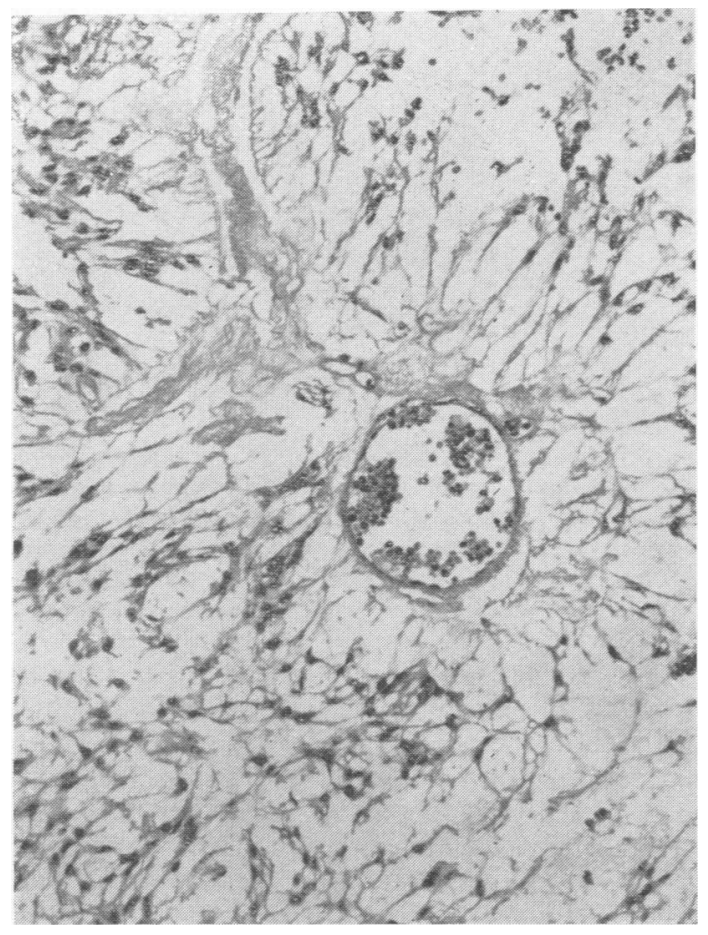

FIG. 4. Tumour originally removed from the region of the cauda equina 27 years before death. Fine fibrillated glial cells with tapering processes orientated towards a central blood vessel. $H$ and $E, \times 160$.

equina. Some of them, originally designated as 'myxopapillary' by Kernohan (1932), form a distinct clinicopathological entity associated with a fairly typical and easily recognizable histological picture. Others, however, do not show the mucinous degeneration of the connective tissue stroma which is diagnostic of these ependymomas, and are papillary, or, as in the present case, possess less distinctive histological features. A notable component, demonstrated in this case, is the presence of an abundant vascular connective tissue stroma. This recalls the normal structure of the filum terminale, in which the connective tissue is a continuation of the pia mater. Clinically, ependymomas in this region present as cauda equina tumours, but the filum terminale or the conus medullaris are generally accepted to be their site of origin. In some cases the conus and the proximal part of the filum are grossly expanded by a soft reddish, well-circumscribed tapering mass, but in others the tumour is infiltrative, spreading along the roots of the cauda equina and rupturing through the dural sheath.

These neoplasms grow slowly and, after invasion

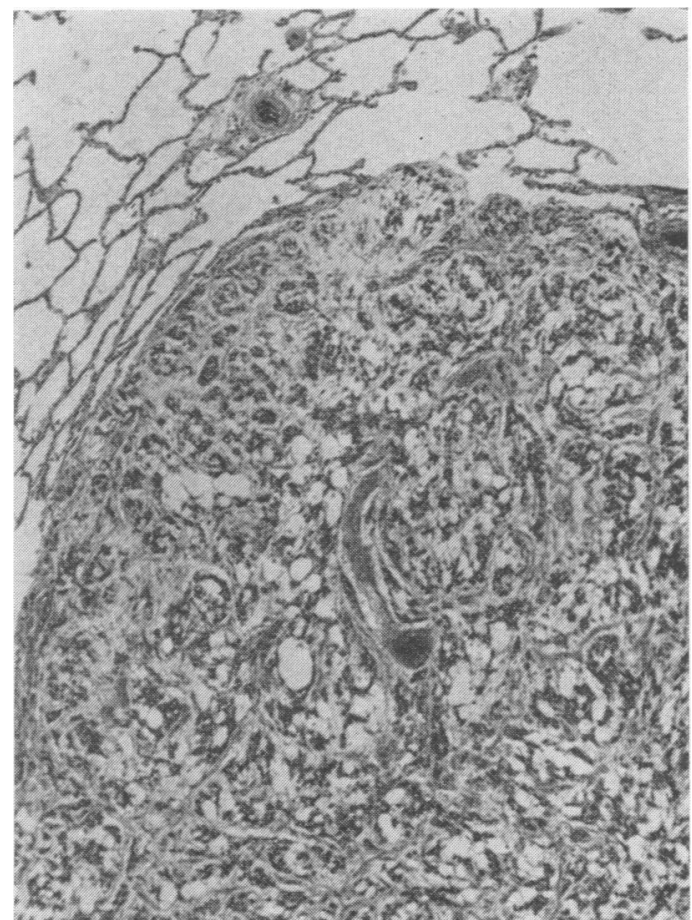

FIG. 5. Low power view of metastatic ependymoma in lower lobe of left lung. $H$ and $E, \times 48$.

of the dura mater, may occasionally form considerable masses that deform and erode the sacrum. They may subsequently extend massively into the lumbosacral vertebrae and the extravertebral soft tissues, but cytological evidence of malignancy is extremely infrequent. It has been seen previously only once by us (L.J.R.).

The development, in this case, of a second tumour diagnosed as ependymoma and removed from the fourth ventricle approximately six years after surgical extirpation of the spinal growth, merits brief discussion. The presumption that the patient had two independent ependymomas cannot be excluded, but has little to support it in view of the identical microscopical appearances of the tumour in both situations. The second possibility, favoured at the time of removal of the fourth ventricle mass, is that the ependymoma originally arose in the fourth ventricle and subsequently metastasized caudally. This seems unlikely in view of the clinical history, according to which the sacral tumour had evidently antedated the intracranial neoplasm by several years, and in view of the subsequent evolution of the case, which was 


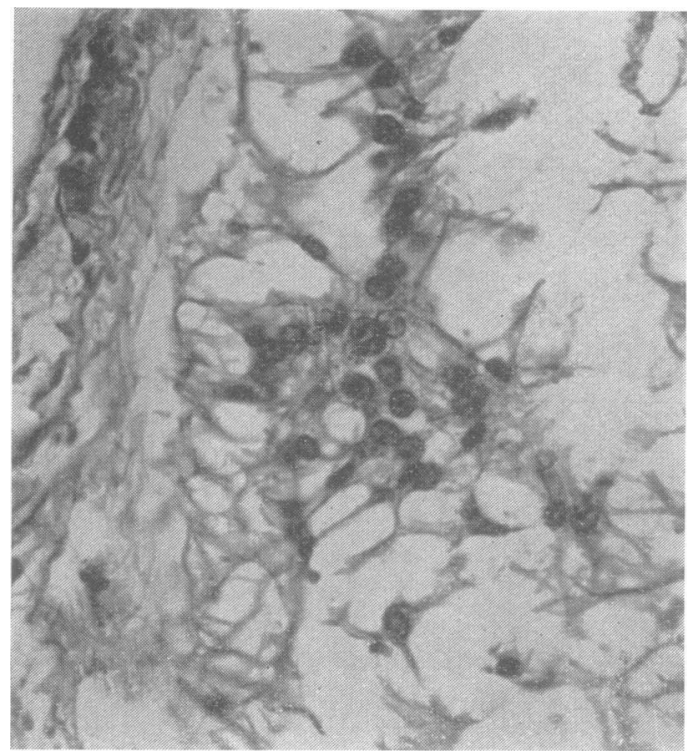

FIG. 6. Cytology of metastatic ependymoma in upper lobe of right lung. Cells with delicate tapering processes attached to fibrous edge of the tumour. $H$ and $E, \times 400$.

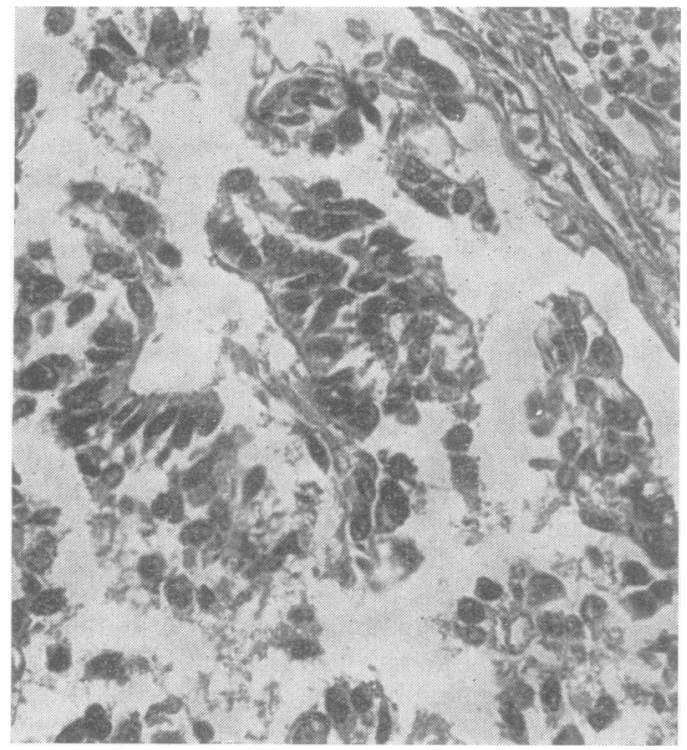

FIG. 7. Metastatic ependymoma in para-aortic lymph node. Cuboidal cells arranged in compact groups suggesting abortive attempt at forming ependyma-lined space. $H$ and $E$, $\times 300$.

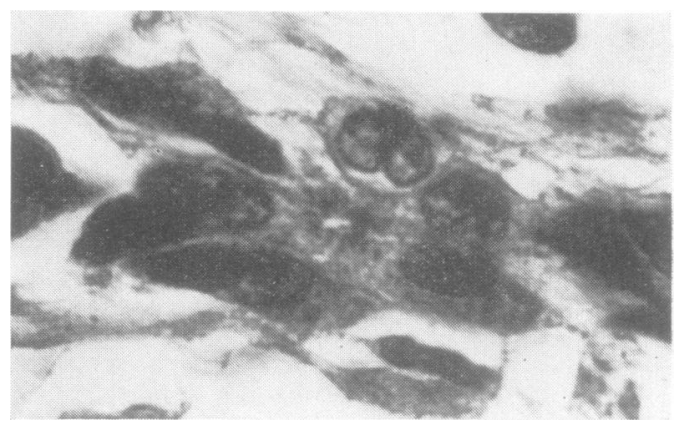

FIG. 8. Metastatic ependymoma in para-aortic lymph node. Small cluster of tumour cells arranged around a small circular lumen, with darkly staining blepharoplasts adjacent to the luminal margin. Mallory's phosphotungstic acid haematoxylin, $\times 1,200$.

closely similar to that of the three other reported examples of ependymomas of the cauda equina with distant metastases. Although downward seeding from an intracranial tumour to the thecal sac occurs in general far more frequently, retrograde spread from a spinal glioma into the intracranias cavity is well-recognized (see Russell and Rubin $\mathbb{\Phi}$ stein, p. 214, 1963), and we believe this to have been the sequence of events in this case.

The development of remote extraneural metastases from ependymomas of the cauda equina has so fap seldom been reported. The literature records onl three acceptable instances which were completel examined at necropsy. Their salient features, as welf as those of the present case, are listed in the Table. All four cases fulfilled the criteria proposed by Weiss (1955) for the acceptance of extraneural metastases from a tumour originating from the central nervous system-namely, (1) the microscopical demonstration of a single histologically characteristic neoplasm of the central nervous system; (2) evidence that the initial symptoms were due to the tumour; $(3)$ the performance of a complete necropsy, conducted in sufficient detail to rule out the possibility of another primary site; and (4) the identity of the morphological features of the central nervous system tumour with those of the distant deposits. For these reasons the example recorded by Christensen (1958), of a large sacral neoplasm in a $5 \frac{1}{2}$ year old boy, diagnosed as a 'malignant neuroepithelioma' and later as 'ependymoma of epithelial type', that filled the pelvis, invaded the sacrum, and caused liver metastases, is excluded since there was no necropsy and the report is not supported by illustrations. Smith et al (1969) briefly refer, in their series of 35 gliomas with extraneural metastases, to one example in the cauda equina of "primitive neuroectodermal 
TABLE

REPORTED NECROPSIED CASES OF EPENDYMOMA OF THE CAUDA EQUINA WITH EXTRANEURAL METASTASES

\begin{tabular}{|c|c|c|c|c|c|c|}
\hline Reference & $\begin{array}{l}\text { Age of } \\
\text { onset }(y r)\end{array}$ & Sex & $\begin{array}{l}\text { Total length of } \\
\text { clinical history }(y r)\end{array}$ & Operations & Vascular invasion & $\begin{array}{c}\text { Sites of metastatic } \\
\text { deposits }\end{array}$ \\
\hline Weiss (1955) & 22 & $\mathbf{M}$ & 10 & 4 & $\begin{array}{l}\text { Common iliac veins, inferior } \\
\text { vena cava, pulmonary arteries }\end{array}$ & $\begin{array}{l}\text { Liver, lungs, hilar lymph } \\
\text { nodes, mediastinum, chest } \\
\text { wall }\end{array}$ \\
\hline $\begin{array}{l}\text { Sharma } \\
\text { (1956) }\end{array}$ & 29 & $\mathbf{M}$ & 4 & 3 & Hepatic veins, renal vein & $\begin{array}{l}\text { Liver, lungs, pleura, media- } \\
\text { stinum, chest wall }\end{array}$ \\
\hline $\begin{array}{l}\text { Patterson } \\
\quad \text { et al (1961) }\end{array}$ & 25 & $F$ & 17 & 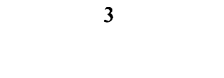 & $\begin{array}{l}\text { Iliac veins, ovarian veins, in- } \\
\text { ferior vena cava }\end{array}$ & $\begin{array}{l}\text { Liver, lungs, pleura, media- } \\
\text { stinum, hilar and aortic } \\
\text { lymph nodes }\end{array}$ \\
\hline Present case & 17 & $\mathbf{F}$ & 29 & $\begin{array}{l}3 \text { (including } 1 \text { sub- } \\
\text { occipital craniotomy } \\
\text { and } 1 \text { needle biopsy) }\end{array}$ & $\begin{array}{l}\text { Common iliac veins, inferior } \\
\text { vena cava }\end{array}$ & $\begin{array}{l}\text { Fourth ventricle, lungs, pleura, } \\
\text { para-aortic lymph node }\end{array}$ \\
\hline
\end{tabular}

tumour' with 'definite glial pattern histologically', in a male, aged 24 at death, who developed metastases in the lung after a total course of 10 months. This case is unlikely to fall into the present group, since it closely resembled a medulloblastoma. The case interpreted by Watt (1968) as an ependymoma of the cauda equina with distant metastases, in a 56 year old woman who had a large cavity in the upper lobe of the left lung and two distinct tumours in the cerebrum, is unacceptable, since the clinical features, gross findings, and microscopical description all point, in our view, to a metastatic adenocarcinoma, in all probability bronchogenic.

Common to all four examples tabulated in the Table is the eventual development of a large invasive mass which infiltrated the lumbosacral vertebrae and adjacent soft tissues. In three cases the total length of the clinical history extended to 10 years or more. Multiple operations, usually over long intervals, were performed in three instances. Vascular invasion, especially of the iliac veins and inferior vena cava, was demonstrated in all. The metastatic deposits most often involved the liver, lungs, pleura, mediastinum, hilar, and periaortic lymph nodes. In three instances, massive local invasion and the development of extraneural metastases remained unaccompanied by malignant cytological change. In the present case, however, marked anaplasia was found in a few areas at the primary site, including portions of the tumour that permeated the iliac veins. Whereas the possibility that anaplastic changes may have been spontaneous cannot be excluded, this seems unlikely, since they were entirely lacking in the distant deposits. The more likely explanation, therefore, is that they were in all probability the result of irradiation. Similar morphological changes have long been known to occur in irradiated experimental brain tumours (Tansley and Wilson, 1947; Netsky, Shapiro, Hoffman, Corsentino, Freid, and
Zimmerman, 1956), and have more recently been described in human cerebellar medulloblastoma (Oppenheimer, 1969).

The pathway of distant dissemination, in this as well as in the other reported cases, is presumed to have occurred via the blood stream. The frequency with which, in published reports, venous permeation is noted to have occurred in gliomas with extraneural metastasis has previously been emphasized. This feature has also been demonstrated in the exceptional instance in which extracranial deposits developed in the absence of previous craniotomy (Rubinstein, 1967). Whereas in some cases venous invasion was recorded only in distant sites, particularly the lungs, in some examples it was found at the primary locus, either in a main sinus or in dural veins within the intracranial cavity, or, as in the cases reviewed in this report, in the large pelvic and abdominal veins. The present observation therefore reinforces the view that, although venous permeation by a glioma is extremely rare, it should, when demonstrated at the primary site, be regarded as a harbinger of distant metastatic spread.

We are grateful to Dr. J. W. Hanbery, Stanford University School of Medicine, for access to the clinical records of this case; to Dr. Nicholas K. Gonatas, University of Pennsylvania, and to the New York Neurological Institute respectively for information on the early clinical history and for making available to us the surgical biopsy material for review. This work was supported by Graduate Neuropathology Training Grant No. 5 TO1 NB05500-04, of the National Institute of Neurological Diseases and Stroke, U.S. Public Health Service.

\section{REFERENCES}

Christensen, E. R. (1958). Presacral and sacral tumours in children. Dan. med. Bull., 5, 25-32. 
Kernohan, J. W. (1932). Primary tumors of the spinal cord and intradural filum terminale. In Cytology and Cellular Pathology of the Nervous System, vol. 3, pp 993-1025, edited by W. Penfield. Hoeber: New York.

Netsky, M. G., Shapiro, J., Hoffman, M., Corsentino, B., Freid, J. R., and Zimmerman, H. M. (1956). The effects of single doses of roentgen radiation on experimentally induced gliomas: with a critical review of the effects of roentgen radiation on gliomas in man. Amer. J. Roentgenol., 76, 351-366.

Oppenheimer, D. R. (1969). The effect of irradiation on a medulloblastoma. J. Neurol. Neurosurg. Psychiat., 32, 94-98.

Patterson, R. H., Jr., Campbell, W. G., Jr., and Parsons, H. (1961). Ependymoma of the cauda equina with multiple visceral metastases. Report of a case. J. Neurosurg., 18, 145-150.

Rubinstein, L. J. (1967). Development of extracranial metastases from a malignant astrocytoma in the absence of previous craniotomy. Case report. J. Neurosurg., 26, 542-547.

Russell, D. S., and Rubinstein, L. J. (1963). Pathology of Tumours of the Nervous System, 2nd edn. Edward Arnold: London.

Sharma K. D. (1956). A metastasizing ependymoma of the cauda equina. Indian $J$. med. Sci., 10, 639-641.

Smith, D. R., Hardman, J. M., and Earle, K. M. (1969). Metastasizing neuroectodermal tumors of the central nervous system. J. Neurosurg., 31, 50-58.

Tansley, K., and Wilson, C. W. (1947). Irradiation of experimental cerebral tumours: experimental production of brain tumours in mice; some observations on effect of $\mathrm{x}$-radiation on experimental gliomata in mice. Radiology, 49, 62-71.

Watt, V. (1968). Ependymoma of the cauda equina with distant metastases: case report. J. Neurosurg., 29, 424-426.

Weiss, L. (1955). A metastasizing ependymoma of the cauda equina. Cancer (Philad.), 8, 161-171. 